OPEN ACCESS

Edited by:

Alexandrina L. Dumitrescu, Dental Private Practice, Bucharest,

Romania

Reviewed by:

Pia Lopez Lopez Jornet, Universidad de Murcia, Spain

Giada Pietrabissa,

Istituto Auxologico Italiano (IRCCS),

Italy

*Correspondence:

Svenja L. Kopp

svenja.kopp@uniklinik-freiburg.de

Specialty section:

This article was submitted to Psychology for Clinical Settings, a section of the journal

Frontiers in Psychology

Received: 30 November 2016 Accepted: 14 February 2017

Published: 28 February 2017

Citation:

Kopp SL, Ramseier CA,

Ratka-Krüger $P$ and Woelber JP (2017) Motivational Interviewing As an Adjunct to Periodontal Therapy $-A$ Systematic Review.

Front. Psychol. 8:279. doi: 10.3389/fpsyg.2017.00279

\section{Motivational Interviewing As an Adjunct to Periodontal Therapy-A Systematic Review}

\author{
Svenja L. Kopp ${ }^{1 *}$, Christoph A. Ramseier ${ }^{2}$, Petra Ratka-Krüger ${ }^{1}$ and Johan P. Woelber ${ }^{1}$ \\ ${ }^{1}$ Department of Operative Dentistry and Periodontology. University Freiburg Medical Center, Freiburg im Breisgau, Germany, \\ ${ }^{2}$ Department of Periodontology and Fixed Prosthodontics, University of Bern, School of Dental Medicine, Bern, Switzerland
}

Aim: Periodontal therapy is highly dependent on a patient's long-term adherence with regard to oral hygiene, diet, and regular check-ups at the dentist. Motivational Interviewing (MI) is a client-centered, directive method for encouraging a patients' behavioral health change. The aim of this systematic review was to reveal the effects of $\mathrm{Ml}$ as an adjunct to periodontal therapy.

Methods: Three databases (PubMed, Cochrane Library, and Web of Science) were reviewed for randomized controlled clinical trials. Articles were included when using MI as an adjunct to periodontal therapy and presenting clinical periodontal and oral hygiene related parameters. Two authors independently coded the relevant articles.

Results: The search yielded 496 articles. After analysis and exclusion, a total of five papers could be included. The quality of the articles ranged between $72-88 \%$. The two independent raters showed a high inter-rater reliability (Cohens-Kappa $=0.89$ ). In two studies Ml showed a significant positive effect on bleeding on probing and plaque values. One study showed improvement of self-efficacy in interdental cleaning. Two studies showed no influence of $\mathrm{Ml}$ on periodontal parameters of the patients.

Conclusion: The use of $\mathrm{Ml}$ as an adjunct to periodontal therapy might have a positive influence on clinical periodontal parameters (plaque values, gingival, and periodontal inflammation) and psychological factors related to oral hygiene (self-efficacy). Due to the low body of evidence further studies are needed. Future studies should include fidelity measures of the applied Ml, a high number of counselors, several Ml sessions, and long-term study follow-up to show potential effects.

Keywords: motivational interviewing, motivational intervention, periodontal therapy, periodontal diseases, systematic review

\section{INTRODUCTION}

Periodontal disease is one of the major chronic inflammatory diseases of mankind and is affecting about 743 million people worldwide (Kassebaum et al., 2014). Long term success of periodontal therapy crucially depends on a patient's adherence behavior to professional recommendations (e.g., regarding regularly follow-up, smoking cessation, or oral hygiene) (Axelsson et al., 2004; Ramseier, 2005; Eickholz et al., 2008). A current consensus report on principles in preventing periodontal disease emphasized the value of proper oral hygiene and smoking cessation in periodontal 
practice (Tonetti et al., 2015). Thus, health behavior communication is a key element to support patient's health behavior change in both periodontal therapy and the prevention of periodontitis. Motivational Interviewing (MI, Miller and Rollnick, 2012) is an evidence-based communication method for supporting health behavior change in several fields like weight reduction, smoking cessation, reduction of alcohol consumption, and control of blood sugar (Lundahl et al., 2013; Ekong and Kavookjian, 2016; Jassal et al., 2016). MI is summarily defined as a "collaborative counseling style for strengthening a person's own motivation and commitment to change" (Miller and Rollnick, 2012, 2014). In the field of oral health, MI showed promising effects on preventing caries cavities in children with a high risk of caries and on decreasing dental plaque by improving oral health and oral health knowledge (Godard et al., 2011; Naidu et al., 2015; Albino and Tiwari, 2016; Gauba et al., 2016).

Correspondingly, MI could principally be useful as a tool for motivating patients with periodontal disease. Interestingly, this suggestion was already mentioned in the consensus report on the principles in preventing periodontal disease and the descriptions for the European core curriculum for both undergraduate dental students and postgraduate dental students (Sanz and Meyle, 2010; Tonetti et al., 2015).

A recent systematic review about the use of $\mathrm{MI}$ in dental settings by Gao et al. (2014) showed positive, but varying effects of MI especially on improving periodontal health through oral hygiene measurements. Looking closer on the included studies a broad variance could be found regarding the measured indices (plaque, gingival bleeding, psychological parameters, pocket probing depths) and the patients included (from healthy to severe periodontal conditions). Because the review by Gao et al. (2014) aimed to present a wider perspective on MI in dental settings and not as an adjunct to periodontal therapy, a more focused discussion and bias rating regarding the periodontal studies was not performed. Thus, it is still unclear if MI is an evidence-based method for health behavior change in periodontal therapy.

Due to this background, the current systematic review aimed to analyze studies specifically regarding the effect of MI as an adjunct to periodontal therapy.

\section{MATERIALS AND METHODS}

The systematic review was based upon PRISMA-P (preferred reporting items for systematic reviews and meta-analyses protocols) and contained the PICO elements (participants, intervention, comparison, outcomes) for conducting this study (Moher et al., 2015). Three databases, Cochrane Library, Web of Science (Thomson Reuters), and Medline (PubMed), were searched for relevant reports by two independent raters (SLK, CAR). In case of non-available publications Google scholar was checked for access.

The protocol for this systematic review was registered on PROSPERO (Registration Number: CRD42017056450).
The following research questions were targeted for this study:

- Which effect does MI have as an adjunct to periodontal therapy?

- Which effect does MI have on the oral hygiene of the periodontal compromised patient?

- Which effect does the duration of motivational interviewing application have on study outcomes?

\section{Search Strategy}

Regarding PICO, the population was defined through the following key words: "periodontitis," "gingivitis," "periodontal," "oral," "dental," und "plaque" were connected with the Boolean operator "OR."

To determine the intervention, the key words "motivational interviewing," "motivational interview," and "motivational intervention" were used. These words were connected with the Boolean operator "OR."

Both, the population and the intervention were connected with the Boolean operator "AND."

Comparators and outcomes were not included in the search term due to the low number of available studies and in order to receive the maximum of publications.

\section{Syntax for both Databases}

(motivational interviewing OR motivational interview $\mathrm{OR}$ motivational intervention) AND (periodontitis OR gingivitis OR periodontal OR oral OR dental OR plaque)

Reference lists of included studies were checked for further studies.

Search for ongoing trials or trials completed but not published were conducted in ClinicalTrials.gov and the WHO International Clinical Trials Registry Platform (ICTRP).

The search was performed for studies published before July 2016.

\section{Data Collection}

Two authors coded with an inter-rater reliability of $99.80 \%(\mathrm{Po}=$ 0.9980, Cohens-Kappa $=0.888$ ).

\section{Inclusion Criteria}

- Randomized controlled clinical trial

- Patients with periodontal disease

- At least one plaque index (PI) and one inflammatory index (e.g., gingival index-GI, bleeding on probing index-BOP).

\section{Exclusion Criteria}

- The use of MI in another area of dentistry than periodontology (e.g., pedodontics)

- The use of MI in other medical areas (alcohol consumption, smoking, drug usage)

- Other study designs than RCTs (e.g., case control studies, cohort studies).

Excluded papers were listed for each database, including the reasons for the exclusion (Table $\mathbf{1}$ ). 


\section{Risk of Bias}

In this systematic review the risk of bias was examined including the external (e.g., generalization) and internal validity (e.g., reliability). The risk of bias items were based upon Lundahl et al. (2013) regarding the MI-related bias, Schmidt et al. (2014) regarding the periodontal study-related bias, and the German version of the Cochrane Collaboration manual (Schmucker et al., 2016) regarding the general bias. Each item was rated and listed. The ratings of the individual domains are shown for each study in Table 2.

The MI-related bias assessment intended to provide a qualitative overview of the application of MI (Miller and Rollnick, 1991, 2002, 2012; Lundahl et al., 2013). Accordingly, the following quality factors were checked:

- The MI version should be mentioned (Miller and Rollnick, 1991, 2002, 2012)

- To avoid personal influences (like sympathy, friendliness), it is important to perform the interventions by a high number of counselors

- The duration and number of interventions should be given to indicate the intensity of MI

- The training of the counselors should be mentioned

- The quality of the interventions should be assessed to evaluate the quality and application of MI.

The periodontal study-related bias provides the bias related to periodontal therapy. Following factors were checked (Schmidt et al., 2014):

- Report of the patients' selection whether the patients were diagnosed with chronic periodontitis

- Report of the periodontal therapy (non-surgical periodontal therapy or surgical periodontal therapy)

- Report about the evaluated indices

- Report or control of periodontal risk factors (e.g., smoking status, intake of medication, diabetes)

- Calibration of the rater regarding the clinical measurements.

The general bias report was about the reliability and validity of the study results. This included the following factors (Schmucker et al., 2016):

- Study design, randomization, and blinding

- Comparability of the patient groups to avoid different group characteristics

- Definition of the experimental and control groups

- The number of therapists report of the equal clinical measurements without distortion due to different measurement techniques. Furthermore, the studies should present all significant results and the funding in a transparent manner.

Each item of the rating scale was rated with one point when meeting the criteria. If the information was not given in the study, it was rated with "not applicable" (n.a.). When not meeting the criteria the item was rated with zero points. At the end, a percentaged total score was built (Schmucker et al., 2016). The risk of bias checklist with its criteria is available under the supplementary file "Data Sheet 2."
TABLE 1 | Excluded studies after full text analysis.

\begin{tabular}{llc}
\hline $\begin{array}{l}\text { First author (year of } \\
\text { publication) }\end{array}$ & Data source & $\begin{array}{c}\text { Reason for } \\
\text { exclusion }\end{array}$ \\
\hline Lhakhang et al., 2016 & E & N2 \\
Harrison, 2014 & E & N3 \\
Shamani and Jansson, 2012 & E & N1 \\
Godard et al., 2011 & E & N2 \\
Yeung, 2010 & E & N3 \\
Neves et al., 2015 & E & N2 \\
Suresh et al., 2012 & E & N2 \\
Halvari and Halvari, 2006 & E & N2 \\
Lhakhang et al., 2015 & E & N2 \\
Almomani et al., 2009 & E & N2 \\
Jönsson et al., 2009a & E & N4 \\
Halvari et al., 2012 & E & N2
\end{tabular}

E, electronical search of database; N1, not related to MI; N2, not related to periodontal therapy by using GI/ BOP and PI, N3, Commentary, Case report, N4, not controlled.

\section{RESULTS}

\section{Screening}

In total the review yielded 496 articles. Forty Three Reviews, five commentaries, two summaries, two not controlled studies, and seven case reports were excluded. After screening titles and abstracts a further 454 articles were excluded. These papers did not involve both inflammatory and plaque indices in combination with motivational interviewing. Regarding the exclusion criteria, in total five papers could be included (Figure 1).

\section{Risk of Bias}

The risk of bias assessment ranged from 72 to $88 \%$ (Table 2). As in the risk of bias is shown, all studies did well in the evaluation. Main limitations were the insufficient presentation of inclusionand exclusion-criteria and the number of counselors. A complete list of all included and excluded articles is presented in the supplementary material (Data Sheet 1).

\section{Study Characteristics and Outcomes}

Three out of the five studies showed that the clinical periodontal values changed significantly in favor of the experimental group using MI as an adjunct to periodontal therapy (Table 3). One study showed a lower BOP in the experimental group compared to the non-MI control group (Jönsson et al., 2010). In two studies gingival inflammation decreased significantly higher in the experimental group than in the control group (Jönsson et al., 2009b; Woelber et al., 2016). In two studies, plaque values showed a significantly higher reduction in the experimental group compared to the control group (Jönsson et al., 2009b, 2010). The combination of multiple MI sessions and long-term study follow up of the patients achieved the best results in a nonsurgical periodontal therapy referring to BOP and PI (Jönsson et al., 2009b, 2010). The study by Woelber et al. (2016) showed a positive effect of MI on plaque values and gingival inflammation with several MI sessions and a treatment period of 6 months. However, the studies with single MI interventions (Stenman 
TABLE 2 | Risk of bias assessment.

\begin{tabular}{|c|c|c|c|c|c|c|}
\hline Risk of Bias & & $\begin{array}{c}\text { Woelber } \\
\text { et al. } \\
(2016)\end{array}$ & $\begin{array}{l}\text { Brand et al. } \\
\qquad(2013)\end{array}$ & $\begin{array}{l}\text { Stenman } \\
\text { et al. (2012) }\end{array}$ & $\begin{array}{l}\text { Jönsson } \\
\text { et al. (2010) }\end{array}$ & $\begin{array}{l}\text { Jönsson } \\
\text { et al. (2009b) }\end{array}$ \\
\hline \multirow[t]{8}{*}{ Ml-Bias } & Type of Ml & n.a. & 1 & 1 & 0 & 0 \\
\hline & Numbers of counselors & 1 & 0 & 0 & 0 & 0 \\
\hline & Ml training of counselors & 1 & n.a. & n.a. & 1 & 1 \\
\hline & Fidelity measure & 1 & 1 & 1 & 1 & 1 \\
\hline & Dose of Ml & 1 & 1 & 1 & 0 & 0 \\
\hline & Number of interventions & 1 & 1 & 1 & 1 & 1 \\
\hline & Profession of counselor & 1 & 0 & 1 & 1 & 1 \\
\hline & Quality of Ml & 1 & n.a. & 0 & n.a. & n.a. \\
\hline \multirow[t]{7}{*}{ Perio-Bias } & Recruitment of patients & 1 & 1 & 1 & 1 & 1 \\
\hline & Type of periodontal therapy & 1 & n.a. & 1 & 1 & 1 \\
\hline & Outcome measures & 1 & 1 & 1 & 1 & 1 \\
\hline & Calibration & 1 & 1 & n.a. & 0 & 0 \\
\hline & Check of medication & 1 & n.a. & n.a. & 1 & 1 \\
\hline & Report of oral hygiene & 1 & 1 & 1 & 1 & 1 \\
\hline & $\begin{array}{l}\text { Report of periodontal risk factors } \\
\text { (e.g., smoking) }\end{array}$ & 1 & 1 & 1 & 1 & 1 \\
\hline \multirow[t]{10}{*}{ General bias } & Study follow-up & 0 & 0 & 1 & 1 & 1 \\
\hline & Randomisation & 0 & 1 & 1 & 1 & 1 \\
\hline & Blinding & 1 & 1 & 1 & 1 & 1 \\
\hline & Inclusion-/ Exclusion criteria & 1 & 1 & 0 & 0 & 0 \\
\hline & Participants (Exp./ control group) & 1 & 1 & 1 & 1 & 1 \\
\hline & $\begin{array}{l}\text { Definition of experimental and } \\
\text { control group }\end{array}$ & 1 & 1 & 1 & 1 & 1 \\
\hline & $\begin{array}{l}\text { Number and profession of } \\
\text { clinicians }\end{array}$ & 1 & 1 & 1 & 1 & 1 \\
\hline & Drop Out & 1 & 1 & 1 & 1 & 1 \\
\hline & Funding & 1 & 1 & 1 & 1 & 1 \\
\hline & Results & 1 & 1 & 1 & 1 & 1 \\
\hline Proportion & & $88 \%$ & $72 \%$ & $76 \%$ & $76 \%$ & $76 \%$ \\
\hline
\end{tabular}

Risk of bias assessment adapted from Lundahl et al. (2013), Schmidt et al. (2014) and Cochrane Handbook from Schmucker et al. (2016). 1, Qualitycriteria fulfilled, 0, not fulfilled, n.a., not applicable.

et al., 2012; Brand et al., 2013) showed no significant differences in periodontal therapy.

Except for one study (Brand et al., 2013), every study evaluated a systematic non-surgical periodontal therapy with additional MI. Woelber et al. (2016) reported about four to five sessions of periodontal therapy. Jönsson et al. (2009b, 2010) performed in their study four to five sessions of periodontal therapy. Stenman et al. (2012) treated the patients with four sessions, which lasted about $1 \mathrm{~h}$. All treatments included initial phase with oral hygiene training, professional tooth cleaning, and SRP. The study by Brand et al. (2013) treated periodontal patients in the supportive periodontal therapy with unknown duration. Woelber et al. (2016) examined patients both in systematic periodontal therapy and supportive periodontal therapy. However, no further analysis between the treatment types was given. The studies showed different periods of study follow-up: Two studies (Brand et al., 2013; Woelber et al., 2016) examined patients 4-6 weeks after completion of the periodontal therapy. Stenman et al. (2012) reevaluated the patients after $2,4,16$, and 26 weeks. Jönsson et al. $(2009 b, 2010)$ examined the clinical assessments after 3, 6, and 12 months. Regarding the MI interventions, in two studies patients received a single session of MI before the systematic periodontal therapy or during SPT (Stenman et al., 2012; Brand et al., 2013). In three studies the patients received multiple MI sessions (Jönsson et al., 2009b, 2010; Woelber et al., 2016).

Regarding the type of counselor, one study included MI sessions conducted by a psychologist specifically trained in MI (Stenman et al., 2012). In three studies the interventions were carried out by in MI trained dental hygienists (Jönsson et al., 2009b, 2010) or in MI trained dental students (Woelber et al., 2016). One further study engaged a consultant trained in MI (Brand et al., 2013). The definition of "consultants" and the extent to which they were trained in MI were not described in detail.

\section{DISCUSSION}

\section{MI as an Adjunct to Periodontal Therapy}

According to the analysis of the studies by Woelber et al. (2016) and Jönsson et al. (2009b, 2010), MI seems to have a positive influence on oral hygiene, periodontal inflammation 
TABLE 3 | Characteristics of included studies.

\begin{tabular}{|c|c|c|c|c|c|}
\hline $\begin{array}{l}\text { Author } \\
\text { Year of publication }\end{array}$ & Woelber et al. (2016) & Brand et al. (2013) & Stenman et al. (2012) & Jönsson et al. (2010) & Jönsson et al. (2009b) \\
\hline $\mathrm{n}$ of patients in total & 155 & 56 & 44 & 113 & 113 \\
\hline n control group & 99 & 27 & 22 & 56 & 56 \\
\hline n experimental group & 73 & 29 & 22 & 57 & 57 \\
\hline Background & $\begin{array}{l}\text { Workshop in Ml for dental } \\
\text { students additional to } \\
\text { non-surgical periodontal } \\
\text { therapy }\end{array}$ & $\begin{array}{l}\text { One Ml-intervention } \\
\text { additional to } \\
\text { periodontal therapy }\end{array}$ & $\begin{array}{l}\text { One Ml-intervention } \\
\text { additional to periodontal } \\
\text { therapy }\end{array}$ & $\begin{array}{l}\text { ITOHEP additional to } \\
\text { periodontal therapy }\end{array}$ & $\begin{array}{l}\text { ITOHEP additional to } \\
\text { periodontal therapy }\end{array}$ \\
\hline Experimental group & $\begin{array}{l}\text { Periodontal therapy treated } \\
\text { by students trained in Ml }\end{array}$ & $\begin{array}{l}\text { One Ml-intervention } \\
\text { before periodontal } \\
\text { therapy }\end{array}$ & $\begin{array}{l}\text { One Ml-intervention } \\
\text { before periodontal } \\
\text { therapy }\end{array}$ & $\begin{array}{l}\text { ITOHEP + periodontal } \\
\text { therapy }\end{array}$ & $\begin{array}{l}\text { ITOHEP + periodontal } \\
\text { therapy }\end{array}$ \\
\hline Control group & $\begin{array}{l}\text { Periodontal therapy treated } \\
\text { by students without } \\
\text { training in } \mathrm{Ml}\end{array}$ & $\begin{array}{l}\text { Periodontal therapy } \\
\text { without additional Ml } \\
\text { intervention }\end{array}$ & $\begin{array}{l}\text { Periodontal therapy } \\
\text { without additional Ml } \\
\text { intervention }\end{array}$ & $\begin{array}{l}\text { Periodontal therapy } \\
\text { without additional Ml } \\
\text { intervention }\end{array}$ & $\begin{array}{l}\text { Periodontal therapy } \\
\text { without additional Ml } \\
\text { intervention }\end{array}$ \\
\hline Type of Ml & n.a. & $\begin{array}{l}\text { Miller and Rollnick } \\
\text { (2002) }\end{array}$ & $\begin{array}{l}\text { Miller and Rollnick (1991, } \\
\text { 2002) }\end{array}$ & $\begin{array}{l}\text { Combination of MI Miller } \\
\text { and Rollnick (2002) and } \\
\text { cognitive behavioral } \\
\text { principles (Bandura, } \\
\text { 1977; Baranowski et al., } \\
\text { 2002) }\end{array}$ & $\begin{array}{l}\text { Combination of MI Miller } \\
\text { and Rollnick (2002) and } \\
\text { cognitive behavioral } \\
\text { principles (Bandura, } \\
\text { 1977; Baranowski et al., } \\
\text { 2002) }\end{array}$ \\
\hline $\begin{array}{l}\text { Number and profession } \\
\text { of counselors }\end{array}$ & 56 dental students & $1 \mathrm{Ml}$ trained counselor & 1 psychologist & 2 dental hygienists & 2 dental hygienists \\
\hline Ml dose & $\begin{array}{l}\text { 4-5, re-evaluation after 4-6 } \\
\text { weeks (duration 2-3 h); } \\
\text { SPT: } 1 \text { appointment }\end{array}$ & $\begin{array}{l}\text { Once after one week } \\
\text { (15-20 min) }\end{array}$ & $\begin{array}{l}\text { One Ml-intervention } \\
\text { before periodontal } \\
\text { therapy ( } 44 \mathrm{~min})\end{array}$ & $\begin{array}{l}\text { Once a week at initial } \\
\text { dental treatment, after } \\
\text { SRP every third month } \\
(3,6,9,12 \text { month) }\end{array}$ & $\begin{array}{l}\text { Once a week at initial } \\
\text { dental treatment, after } \\
\text { SRP every third month } \\
(3,6,9,12 \text { month) }\end{array}$ \\
\hline Clinical measurements & PI, GI, PPD, CAL, BOP & BOP, PI, PPD & $\mathrm{BOP}, \mathrm{PI}$ & PPD, BOP, PI & $\mathrm{GI}, \mathrm{PI}$ \\
\hline $\begin{array}{l}\text { Number and profession } \\
\text { of clinicians }\end{array}$ & 56 dental students & 2 dental hygienists & 4 dental hygienists & $\begin{array}{l}1 \text { periodontal specialist: } \\
\text { clinical measurements } 1 \\
\text { dental hygienist: } \\
\text { treatment of } \\
\text { periodontitis }\end{array}$ & n.a. \\
\hline Follow-up & 0-6 weeks & 6,12 weeks & $2,4,16,26$ weeks & 3 and 12 months & 3 and 12 months \\
\hline $\begin{array}{l}\text { Type and duration of } \\
\text { periodontal therapy }\end{array}$ & $\begin{array}{l}\text { Systematic non-surgical } \\
\text { periodontal therapy; SPT, } \\
\text { ca 4-5 appointments of } \\
\text { 2-3 h }\end{array}$ & $\begin{array}{l}\text { Supportive periodontal } \\
\text { therapy; n.a. duration }\end{array}$ & $\begin{array}{l}\text { Systematic non-surgical } \\
\text { periodontal therapy, } 4 \\
\text { appointments of } 1 \mathrm{~h}\end{array}$ & $\begin{array}{l}\text { Systematic non-surgical } \\
\text { periodontal therapy, 4-5 } \\
\text { appointments; n.a. } \\
\text { duration }\end{array}$ & $\begin{array}{l}\text { Systematic non-surgical } \\
\text { periodontal therapy, 4-5 } \\
\text { appointments of SRP; } \\
\text { n.a. duration }\end{array}$ \\
\hline Drop-Outs & 21 & 3 & 5 & n.a. & 6 \\
\hline $\begin{array}{l}\text { Outcome } \\
\text { measurements }\end{array}$ & $\begin{array}{l}\text { GI, PPD } \downarrow \text { SWE IDR } \uparrow M I T I \\
\uparrow\end{array}$ & $\begin{array}{l}\text { No difference between } \\
\text { trialgroups }\end{array}$ & $\begin{array}{l}\text { No difference between } \\
\text { trialgroups }\end{array}$ & $\mathrm{BOP}, \mathrm{PI} \downarrow$ & GI, PI $\downarrow$ \\
\hline Main findings & $\begin{array}{l}\text { Teaching students in Ml } \\
\text { showed a significant effect } \\
\text { on ID-cleaning self-efficacy } \\
\text { in patients. Ml-adherent } \\
\text { communication was } \\
\text { significantly improved in } \\
\text { students. }\end{array}$ & $\begin{array}{l}\text { The study showed no } \\
\text { effects on oral hygiene } \\
\text { and clinical outcomes } \\
\text { with an additional brief } \\
\text { MI intervention }\end{array}$ & $\begin{array}{l}\text { The study showed no } \\
\text { effects on oral hygiene } \\
\text { and clinical outcomes } \\
\text { with an additional brief Ml } \\
\text { intervention }\end{array}$ & $\begin{array}{l}\text { ITOHEP was efficacious } \\
\text { for improving gingival } \\
\text { and periodontal } \\
\text { inflammation in } \\
\text { periodontal therapy. }\end{array}$ & $\begin{array}{l}\text { ITOHEP was an } \\
\text { efficacious in long term } \\
\text { reduction of gingival and } \\
\text { periodontal } \\
\text { inflammation. }\end{array}$ \\
\hline
\end{tabular}

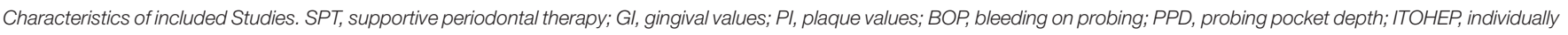
tailored oral health educational programme, MITI, motivational interviewing integrity code, SWE IDR, interdental cleaning self-efficacy; SRP, scaling and root planning.

and psychological oral hygiene factors in periodontal therapy. However, the available data is rather weak. Three out of five studies showed a positive outcome regarding the effects of additional MI interventions in periodontal therapy, while two studies showed no significant effects (Stenman et al., 2012; Brand et al., 2013). Amongst the three studies with positive outcomes, two studies embedded MI in a combination with other behavioral principles like the theory of self-efficacy (Jönsson et al., 2009b,
2010) and one study only found effects on psychological oral parameters (Woelber et al., 2016). Due to this low body of evidence there remains a need for further well-conducted longterm studies.

Nonetheless, no negative results for MI could be found and the shown effects were important factors, because reduced levels of plaque and gingival inflammation determine the long-term success of periodontal therapy (Axelsson et al., 2004; Eickholz 


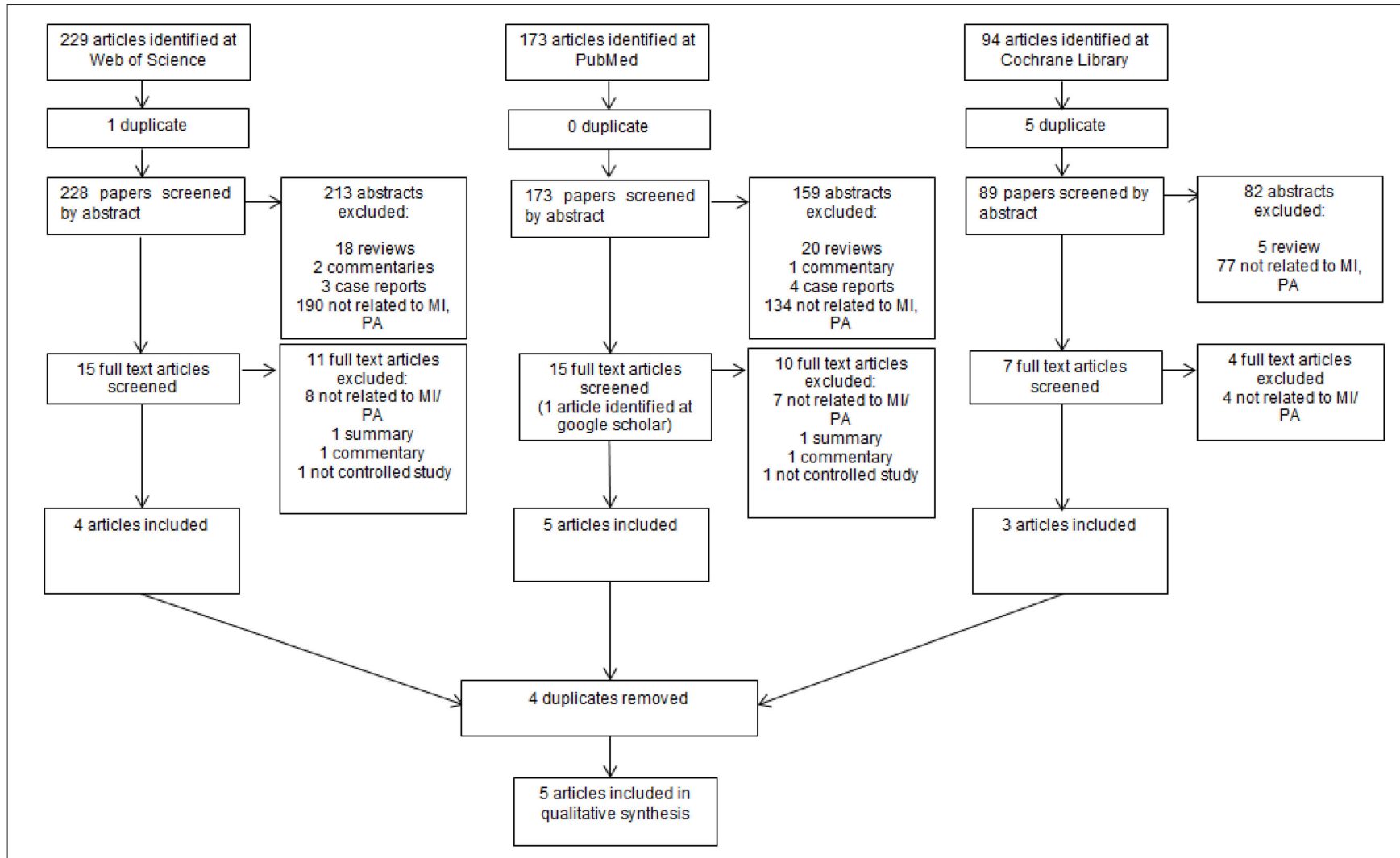

FIGURE 1 | Flow chart of the literature screening.

et al., 2008). Furthermore, the application of MI seems to not be more time consuming than traditional techniques (Woelber et al., 2016).

\section{Duration of the Follow-Up}

Regarding the question how the duration of study follow-up measures in MI-studies is important for the long-term effect, Jönsson et al. (2009b, 2010) conducted a study over a longer term within 12 months, compared to the other studies. These studies showed a significant reduction of BOP, GI, and PI in the MI-group. This positive effect of long-term studies regarding MI might be explainable due to several factors in clinical treatment of periodontal disease, because clinical interventions have a strong short-term effect (like scaling and root planing and professional mechanical plaque removal). Scaling and root planing (SRP) is very effective in the reduction of elevated pocket depths in addition to positive effects on the composition of the subgingival biofilm (Ramfjord et al., 1982; Axelsson et al., 2004; Goodson et al., 2012). Furthermore, sufficient oral hygiene is an important factor in reducing pocket depth values additionally to scaling and root planing (Nyman et al., 1977; Westfelt et al., 1998). A review by Needleman et al. (2015) found out that repeated oral hygiene instructions can achieve comparable results as repeated professional mechanical plaque removal alone. Thus, it is to be expected that behavioral interventions need a longer followup in periodontal studies to show their potential effects. This assumption is supported by Eickholz et al. (2008), who found that the most important risk factor for tooth loss after 10 years was the irregular participation of patients to supportive periodontal therapy. Therefore, it would be important to carry out long-term studies in order to investigate the effect on the motivation of patients to perform oral hygiene and to participate in supportive periodontal treatment regularly. Possible long-term studies could be performed by groups of trained and non-MI-trained dental professionals in separated dental practices. This would also give an impression if MI would be a feasible method in the dental practice and not only in the university setting.

\section{Kind of Used MI in Interventions}

Data analysis revealed a lack of precise information about the kind of MI-interventions in the included studies. Even though there were only minor changes, the definition of Motivational Interviewing changed over the years (Miller and Rollnick, 1991, 2002, 2012). Additionally, due to the variety of methods and principles in MI (e.g., development of discrepancy, clientcentered principles, evocation), the style of MI can differ amongst the counselors. For this, studies with a high number of counselors and a communication manual would be advisable to create an identical framework and to heighten the quality of the study. This manual should also relate to oral hygiene measurements and procedures (like demonstration by the professional and patient himself). Furthermore, the application of MI should not be 
combined with other behavioral interventions like in the studies by Jönsson et al. (2009b, 2010), even though some principles might be also included in MI framework (e.g., the theory of self-efficacy).

\section{Evaluated Outcomes}

In order to receive a comprehensive impression of the periodontal outcomes, only studies were included that investigated at least one inflammatory index and one plaque index (Mombelli et al., 2014). The plaque index serves as an indicator of plaque accumulation and the inflammatory index serves as a long-term parameter for the inflammatory status of the periodontium (Löe et al., 1965). In the recent review of Gao et al. (2014), partly relating to MI and the influence on oral hygiene and improving periodontal health, some of the mentioned studies had to be excluded in this review due to the lack of plaque or gingival indices. Within these studies, one study examined only the knowledge regarding oral hygiene and the self-efficacy in the patients (Stewart et al., 1996). Lalic et al. (2012) evaluated only the BOP of patients. Two studies investigated only plaque values (Almomani et al., 2009; Godard et al., 2011). Thus, the review by Gao et al. (2014) concluded studies with indices which allow only a limited view about the effect of MI on periodontal therapy with no risk of bias analyzation regarding the periodontal therapy. In this current review, the studies of Godard et al. (2011) and Almomani et al. (2009) were primarily included in the literature analysis and finally excluded due to the exclusion criteria (Table 1). Another interesting aspect of the use of MI as an adjunct to periodontal therapy is the broader influence on periodontal risk factors besides oral hygiene. In this context, a study by Schoonheim-Klein et al. (2013) showed a higher effort in smoking cessation of dental students trained in MI compared to non-trained students.

\section{Evaluation of MI-Quality}

From the five included studies, only two studies evaluated and controlled the application and quality of the MI elements (Stenman et al., 2012; Woelber et al., 2016). In the study of Woelber et al. (2016) the MI-trained students attained in average 3.35 points according to German version of the MITI 2.0 (Moyers et al., 2005; Brueck et al., 2009). The students of the control group achieved an average of 1.76 points in this assessment. According to Moyers et al. (2005), the beginning proficiency for MI begins with an average of five points and competency with six points and more. Stenman et al. (2012) performed the MI interventions by a trained psychologist in order to achieve a high quality of used MI elements. According to the MITI 3.0 coding system, average values of $2.5-3.5$ points were achieved. The applied MITI 3.0 according to Moyers et al. (2007) defines competency in MI with values above four points. It should be mentioned that the rating scales of MITI 3.0 and MITI 2.0 are not comparable. However, the fidelity measurement allows an impression about the applied quality of MI and Miller and Rollnick (2014) stated that these information are essential when studies regarding MI are presented. Looking at the MITI values of Woelber et al. (2016) and Stenman et al. (2012) it seems like that in both studies MI was not applied in its full potential. Furthermore, Stenman et al.
(2012) did present the values in general and not in detail for each MITI element in their publication.

\section{Counselor Background}

In addition, it has to be discussed how the professional background of the MI counselor influences the periodontal outcomes. Here, a single MI intervention by a psychologist showed no effect on clinical results in periodontal therapy (Stenman et al., 2012) and in studies with positive MI-outcomes MI was applied by MI-trained dental caregivers (Jönsson et al., 2009b, 2010; Woelber et al., 2016). It can be speculated that patients show more commitment to a health-specific counselor. This might be due the important role of empathy between the patient and the clinical examiner (Walseth and Schei, 2011). A good patient-examiner relationship automatically creates a certain motivation and is important for a long-term adherence of the patient. These assumptions also reveal an inherent bias when investigating the effects of MI in a certain health setting: the strength of the Stenman et al. study regarding the "clean" application of MI by an external psychologist also might weaken the possible effects in a "real" dental setting with a combined MIand dental-expert.

Looking more closely at the study plans, all studies were conducted in a parallel-group design. Only the study by Woelber et al. (2016) treated the patients of the experimental- and controlgroup in a staggered interval, with the idea, that the therapists and patients could not interchange with each other. It should be noted that the seasonal treatment could have a positive or negative impact on the patients and the treatment of the students.

\section{LIMITATIONS}

A general limitation is that no study conducted a "sham exposure." The experimental groups received one or more MI sessions during periodontal therapy, and the control groups received periodontal therapy without additional MI interventions. It should be noted that a control group with training in non-MI-conversation (sham exposure) would be useful in order to avoid a Hawthorne effect of the trainees and the patients (Roethlisberger and Dickson, 1939).

Although the review beyond PubMed is not necessarily beneficial (Halladay et al., 2015), using more than three databases could possibly provide more studies.

\section{SUMMARY}

Taking all of the above under consideration, some important recommendations can be made for future studies:

- Due to the strong short-term clinical effects of scaling and root planing, antibiotics, and professional tooth cleaning, long-term studies are needed to evaluate the effect of MI on periodontal-related health behavior (like oral hygiene, smoking cessation, nutritional change, or patient adherence).

- A standard communication manual should be established in order to control and evaluate the used MI elements and oral hygiene instructions. 
- A high number of dental professionals as study counselors should be trained in MI to a proficiency level to ensure effective use of MI and to avoid personal influences (like sympathy, friendliness etc.).

- Although the studies showed no deterioration of the clinical results due to the efficacy of SRP, several MI interventions seem to have a greater effect on the behavioral change of the patients (Martins and McNeil, 2009).

\section{CONCLUSIONS}

This systematic review showed that the use of Motivational Interviewing as an adjunct to periodontal therapy might have a positive influence on clinical periodontal parameters and psychological factors related to oral hygiene. Due to the low body of evidence further long-term studies are needed.

\section{AUTHOR CONTRIBUTIONS}

SK contributed to planning and conduction of the study and writing the manuscript. CR contributed to planning and conduction of the study and writing the manuscript.

\section{REFERENCES}

Albino, J., and Tiwari, T. (2016). Preventing childhood caries: a review of recent behavioral research. J. Dent. Res. 1, 35-42. doi: 10.1177/00220345156 09034

Almomani, F., Williams, K., Catley, D., and Brown, C. (2009). Effects of an oral health promotion program in people with mental illness. J. Dent. Res. 88, 648-652. doi: 10.1177/0022034509338156

Axelsson, P., Nyström, B., and Lindhe, J. (2004). The long-term effect of a plaque control program on tooth mortality, caries and periodontal disease in adults: results after 30 years of maintenance. J. Clin. Periodontol. 31, 749-757. doi: 10.1111/j.1600-051X.2004.00563.x

Bandura, A. (1977). Self-efficacy: toward a unifing theory of behavioral change. Psychol. Rev. 84, 191-215. doi: 10.1037/0033-295X.84.2.191

Baranowski, T., Perry, C., and Parcel, G. (2002). "How individuals, environments, and health behavior interact," in Health Behavior and Health Education: Theory, Research, and Practice, 3rd Edn. (San Francisco, CA: Jossey-Bass), 165-184.

Brand, V. S., Bray, K. K., MacNeill, S., Catley, D., and Williams, K. (2013). Impact of single-session motivational interviewing on clinical outcomes following periodontal maintenance therapy. Int. J. Dent. Hyg. 11, 134-141. doi: 10.1111 /idh.12012

Brueck, R. K., Frick, K., Loessl, B., Kriston, L., Schondelmaier, S., Go, C., et al. (2009). Psychometric properties of the German version of the motivational interviewing treatment integrity code. J. Subst. Abuse Treat. 36, 44-48. doi: 10.1016/j.jsat.2008.04.004

Eickholz, P., Kaltschmitt, J., Berbig, J., Reitmeir, P., and Pretzl, B. (2008). Tooth loss after active periodontal therapy. 1: patient-related factors for risk, prognosis, and quality of outcome. J. Clin. Periodontol. 35, 165-174. doi: 10.1111/j.1600-051X.2007.01184.x

Ekong, G., and Kavookjian, J. (2016). Motivational interviewing and outcomes in adults with type 2 diabetes: a systematic review. Patient Educ. Couns. 99, 944-952. doi: 10.1016/j.pec.2015.11.022

Gao, X., Lo, E. C., Kot, S. C., and Chan, K. C. (2014). Motivational interviewing in improving oral health: a systematic review of randomized controlled trials. J. Periodontol. 85, 426-437. doi: 10.1902/jop.2013.130205

Gauba, K., Goyal, A., and Mittal, N. (2016). A CAMBRA model for high caries risk indian children: a pragmatic comprehensive tailored intervention. J. Clin. Pediatr. Dent. 40, 36-43. doi: 10.17796/1053-4628-40.1.36
PR contributed to conduction of the study and writing the manuscript. JW contributed to planning and conduction of the study and writing the manuscript.

\section{FUNDING}

The study was based on institutional funding. The article processing charge was funded by the German Research Foundation (DFG) and the Albert Ludwigs University Freiburg in the funding programme Open Access Publishing.

\section{ACKNOWLEDGMENTS}

The authors want to thank the Association for Dental Education in Europe (ADEE) for supporting the research regarding health behavior change.

\section{SUPPLEMENTARY MATERIAL}

The Supplementary Material for this article can be found online at: http://journal.frontiersin.org/article/10.3389/fpsyg. 2017.00279/full\#supplementary-material

Godard, A., Dufour, T., and Jeanne, S. (2011). Application of selfregulation theory and motivational interview for improving oral hygiene: a randomized controlled trial. J. Clin. Periodontol. 38, 1099-1105. doi: 10.1111/j.1600-051X.2011.01782.x

Goodson, J. M., Haffajee, A. D., Socransky, S. S., Kent, R., Teles, R., Hasturk, H., et al. (2012). Control of periodontal infections: a randomized controlled trial I. The primary outcome attachment gain and pocket depth reduction at treated sites. J. Clin. Periodontol. 39, 526-536. doi: 10.1111/j.1600-051X.2012.01870.x

Halladay, C. W., Trikalinos, T. A., Schmid, I. T., Schmid, C. H., and Dahabreh, I. J. (2015). Using data sources beyond PubMed has a modest impact on the results of systematic reviews of therapeutic interventions. J. Clin. Epidemiol. 68, 1076-1084. doi: 10.1016/j.jclinepi.2014.12.017

Halvari, A. E. M., Halvari, H, Bjornebekk, G, and Deci, E. L. (2012). Selfdetermined motivational predictors of increases in dental behaviors, decreases in dental plaque, and improvement in oral health: a randomized clinical trial. Health Psychol. 31, 777-788. doi: 10.1037/a0027062

Halvari, A. E. M., and Halvari, H. (2006). Motivational predictors of change in oral health: an experimental test of self-determination theory. Motiv. Emot. 30, 294. doi: 10.1007/s11031-006-9035-8

Harrison, R. (2014). Motivational interviewing (MI) compared to conventional education (CE) has potential to improving oral health behaviors. J. Evid. Based Dent. Pract. 14, 124-126. doi: 10.1016/j.jebdp.2014.07.012

Jassal, M. S., Riekert, K. A., Borrelli, B., Rand, C. S., and Eakin, M. N. (2016). Cost analysis of motivational interviewing and preschool education for secondhand smoke exposures. Nicotine Tob. Res. 7, 1656-1664. doi: 10.1093/ntr/ntw001

Jönsson, B., Ohrn, K., Lindberg, P., and Oscarson, N. (2010). Evaluation of an individually tailored oral health educational programme on periodontal health. J. Clin. Periodontol. 37, 912-919. doi: 10.1111/j.1600-051X.2010.01590.x

Jönsson, B., Ohrn, K., Oscarson, N., and Lindberg, P. (2009a). An individually tailored treatment programme for improved oral hygiene: introduction of a new course of action in health education for patients with periodontitis. Int. J. Dent. Hyg. 7, 166-175. doi: 10.1111/j.1601-5037.2008. 00350.x

Jönsson, B., Ohrn, K., Oscarson, N., and Lindberg, P. (2009b). The effectiveness of an individually tailored oral health educational programme on oral hygiene behaviour in patients with periodontal disease: a blinded randomizedcontrolled clinical trial (one-year follow-up). J. Clin. Periodontol. 36, 1025-1034. doi: 10.1111/j.1600-051X.2009.01453.x 
Kassebaum, N. J., Bernabé, E., Dahiya, M., Bhandari, B., Murray, C. J., and Marcenes, W. (2014). Global Burden of Severe Periodontitis in 1990-2010 a systematic review and meta-regression. J. Dent. Res. 93, 1045-1053. doi: $10.1177 / 0022034514552491$

Lalic, M., Aleksic, E., Gajic, M., Milic, J., and Malesevic, D. (2012). Does oral health counseling effectively improve oral hygiene of orthodontic patients? Eur. J. Paediatr. Dent. 13, 181-186.

Lhakhang, P., Gholami, M., Knoll, N., and Schwarzer, R. (2015). Comparing a motivational and a self-regulatory intervention to adopt an oral self-care regimen: a two-sequential randomized crossover trial. Psychol. Health Med. 20, 381-392. doi: 10.1080/13548506.2014.951368

Lhakhang, P., Hamilton, K., Sud, N., Sud, S., Kroon, J., Knoll, N., et al. (2016). Combining self-management cues with incentives to promote interdental cleaning among Indian periodontal disease outpatients. BMC Oral Health 16:6. doi: 10.1186/s12903-016-0164-5

Löe, H., Theilade, E., and Jensen, S. B. (1965). Experimental gingivitis in man. J. Periodontol. 36, 177-187. doi: 10.1902/jop.1965.36.3.177

Lundahl, B., Moleni, T., Burke, B. L., Butters, R., Tollefson, D., Butler, C., et al. (2013). Motivational interviewing in medical care settings: a systematic review and meta-analysis of randomized controlled trials. Patient Educ. Couns. 93, 157-168. doi: 10.1016/j.pec.2013.07.012

Martins, R. K., and McNeil, D. W. (2009). Review of motivational interviewing in promoting health behaviors. Clin. Psychol. Rev. 29, 283-293. doi: 10.1016/j.cpr.2009.02.001

Miller, W. R., and Rollnick, S. (1991). Motivational Interviewing. Preparing People to Change Addictive Behaviors. New York, NY: Guilford Press.

Miller, W. R., and Rollnick, S. (2002). Motivational Interviewing: Preparing People for Change. New York, NY: Guilford Press.

Miller, W. R., and Rollnick, S. (2012). Motivational Interviewing: Helping People Change. New York, NY: Guilford Press.

Miller, W. R., and Rollnick, S. (2014). The effectiveness and ineffectiveness of complex behavioral interventions: impact of treatment fidelity. Contemp. Clin. Trials 37, 234-241. doi: 10.1016/j.cct.2014.01.005

Moher, D., Shamseer, L., Clarke, M., Ghersi, D., Liberati, A., Petticrew, M., et al. (2015). Preferred reporting items for systematic review and meta-analysis protocols (PRISMA-P) 2015 statement. Syst. Rev. 4:1. doi: 10.1186/2046-4053-4-1

Mombelli, A., Schmid, J., Walter, C., and Wetzel, A. (2014). Qualitätsleitlinien. Swiss Dent. J. 2, 261-267. doi: 10.1111/j.1600-051X.2005.00690.x

Moyers, T. B., Martin, T., Manual, J. K., Miller, W. R., and Ernst, D. (2007). Revised Global Scales: Motivational Interviewing Treatment Integrity 3.0 (MITI 3.0). 28. 2007. University of New Mexico, Center on Alcoholism. Substance Abuse and Addictions (CASAA).

Moyers, T. B., Martin, T., Manuel, J. K., Hendrickson, S. M., and Miller, W. R. (2005). Assessing competence in the use of motivational interviewing. J. Subst. Abuse Treat. 28, 19-26. doi: 10.1016/j.jsat.2004.11.001

Naidu, R., Nunn, J., and Irwin, J. D. (2015). The effect of motivational interviewing on oral healthcare knowledge, attitudes and behaviour of parents and caregivers of preschool children: an exploratory cluster randomised controlled study. BMC Oral Health 15:101. doi: 10.1186/s12903-015-0068-9

Needleman, I., Nibali, L., and Di Iorio, A. (2015). Professional mechanical plaque removal for prevention of periodontal diseases in adults-systematic review update. J. Clin. Periodontol. 42(Suppl. 16), S12-S35. doi: 10.1111/jcpe.12341

Neves, P. C. B., Cortellazzi, K. L., Ambrosano, G. M. B., Pereira, A. C., de Castro Meneghin, M., and Mialhe, F. L. (2015). The impact of motivational interviewing in reducing plaque and bleeding indices on probing in adult users of the family health strategy. Braz. Res. Pediatr Dent. Integrated Clin. 15, 183-196. doi: 10.4034/PBOCI.2015.151.20

Nyman, S., Lindhe, J., and Rosling, B. (1977). Periodontal surgery in plaque-infected dentitions. J. Clin. Periodontol. 4, 240-249. doi: 10.1111/j.1600-051X.1977.tb01896.x

Ramfjord, S. P., Morrison, E. C., Burgett, F. G., Nissle, R. R., Shick, R. A., Zann, G. J., et al. (1982). Oral hygiene and maintenance of periodontal support. J. Periodontol. 53, 26-30. doi: 10.1902/jop.1982.53.1.26

Ramseier, C. A. (2005). Potential impact of subject-based risk factor control on periodontitis. J. Clin. Periodontol. 32(Suppl. 6), 283-290. doi: 10.1111/j.1600-051X.2005.00798.x
Roethlisberger, F. J., and Dickson, W. J. (1939). Management and the Worker An Account of a Research Program Conducted by the Western Electric Co. Hawthorne Works, Chicago. Cambridge, MA: Harvard University Press.

Sanz, M., and Meyle, J. (2010). Scope, competences, learning outcomes and methods of periodontal education within the undergraduate dental curriculum: a consensus report of the 1st European workshop on periodontal education 2013; position paper 2 and consensus view 2. Eur. J. Dent. Educ. 14, 25-33. doi: 10.1111/j.1600-0579.2010.00621.x

Schmidt, J. C., Walter, C., Amato, M., and Weiger, R. (2014). Treatment of periodontal-endodontic lesions-a systematic review. J. Clin. Periodontol. 41, 779-790. doi: 10.1111/jcpe.12265

Schmucker, C., Nothacker, M., Rücker, G., Muche-Borowski, C., Kopp, I., Meerpohl, J., et al. (2016). Bewertung des Biasrisikos (Risiko Systematischer Fehler) in Klinischen Studien: ein Manual für die Leitlinienerstellung, 1st Edn. Available online at: www.cochrane.de/rob-manual.

Schoonheim-Klein, M., Gresnigt, C., and van der Velden, U. (2013). Influence of dental education in motivational interviewing on the efficacy of interventions for smoking cessation. Eur. J. Dent. Educ. 17, e28-e33. doi: 10.1111/j.1600-0579.2012.00755.x

Shamani, S., and Jansson, L. (2012). Oral hygiene behaviour change during the nonsurgical periodontal treatment phase. Open Dent. J. 6, 190-196. doi: $10.2174 / 1874210601206010190$

Stenman, J., Lundgren, J., Wennström, J. L., Ericsson, J. S., and Abrahamsson, K. H. (2012). A single session of motivational interviewing as an additive means to improve adherence in periodontal infection control: a randomized controlled trial. J. Clin. Periodontol. 39, 947-954. doi: 10.1111/j.1600-051X.2012. 01926.x

Stewart, J. E., Wolfe, G. R., Maeder, L., and Hartz, G. W. (1996). Changes in dental knowledge and self-efficacy scores following interventions to change oral hygiene behavior. Patient Educ. Couns. 27, 269-277. doi: 10.1016/0738-3991(95)00843-8

Suresh, R., Jones, K. C., Newton, J. T., and Asimakopoulou, K. (2012). An exploratory study into whether self-monitoring improves adherence to daily flossing among dental patients. J. Public Health Dent. 72, 1-7. doi: 10.1111/j.1752-7325.2011.00274.x

Tonetti, M. S., Eickholz, P., Loos, B. G., Papapanou, P., van der Velden, U., Armitage, G., et al. (2015). Principles in prevention of periodontal diseases: consensus report of group 1 of the 11th European Workshop on Periodontology on effective prevention of periodontal and peri-implant diseases. J. Clin. Periodontol. 42(Suppl. 16), S5-S11. doi: 10.1111/jcpe. 12368

Walseth, L. T., and Schei, E. (2011). Effecting change through dialogue: Habermas' theory of communicative action as a tool in medical lifestyle interventions. Med. Health Care Philos. 14, 81-90. doi: 10.1007/s11019-0109260-5

Westfelt, E., Rylander, H., Dahlén, G., and Lindhe, J. (1998). The effect of supragingival plaque control on the progression of advanced periodontal disease. J. Clin. Periodontol. 25, 536-541. doi: 10.1111/j.1600-051X.1998.tb02484.x

Woelber, J. P., Spann-Aloge, N., Hanna, G., Fabry, G., Frick, K., Brueck, R., et al. (2016). Training of dental professionals in motivational interviewing can heighten interdental cleaning self-efficacy in periodontal patients. Front. Psychol. 7:254. doi: 10.3389/fpsyg.2016.00254

Yeung, C. A. (2010). Motivational interviewing in an oral health promotion programme. Evid. Based Dent. 11, 14-15. doi: 10.1038/sj.ebd.6400703

Conflict of Interest Statement: The authors declare that the research was conducted in the absence of any commercial or financial relationships that could be construed as a potential conflict of interest.

Copyright $\odot 2017$ Kopp, Ramseier, Ratka-Krüger and Woelber. This is an openaccess article distributed under the terms of the Creative Commons Attribution License (CC BY). The use, distribution or reproduction in other forums is permitted, provided the original author(s) or licensor are credited and that the original publication in this journal is cited, in accordance with accepted academic practice. No use, distribution or reproduction is permitted which does not comply with these terms. 